\section{B00K REVIEW}

\section{Fertility and Conception (3rd edn)}

Karen Trewinnard. London, UK: Carroll \& Brown Publishers, 2010. ISBN-13: 978-1-90476-074-0. Price: f14.99. Pages: 190 (paperback)

This is a well-written, easy-to-read guide for women trying to conceive. It is the third edition, having been first published in 1999. There are lots of useful illustrations, tables and text boxes. The first chapter educates the layperson about their reproductive function, while the second chapter gives tips to maximise their chance of conception.

The book contains a useful summary of the forms of contraception available and an excellent account on lifestyle and nutrition, not just for those trying to conceive. It conveys a responsible message to quit habits such as smoking, alcohol and drugs, which of course are damaging habits to fertility and the health of the mother and unborn child. The section on environmental hazards is thoroughly illuminating - if not alarming - and does draw attention to some often overlooked causes of infertility. I enjoyed the easy-to-read section on sexually transmitted infections. Some sections, including the description of the menstrual cycle, were fairly scientific for the intended readership.

I did find it difficult to separate statements supported by evidence from those supported by anecdote. I was disappointed to see some advice that is contrary to national guidance. There was a large section on basal body temperature monitoring, which does not improve conception rates and is not recommended. I was also disappointed to see commentary on postcoital testing and gamete intrafallopian transfer, given that these techniques have also dropped out of national guidance. The section on influencing baby's sex is misleading and has no grounding in evidence-based literature. In the useful addresses section I could not see the largest UK patient charity, Infertility Network UK, but did see the American charity. 'Resolve'.

Despite its flaws, this is nevertheless a good all-round book covering advice on healthy eating, exercise and so on. I would cautiously recommend this book to my patients but stress that they ignore the section on basal body temperature monitoring.

\section{Reviewed by Scott Wilkes}

General Practitioner/Honorary Clinical Senior Lecturer, Newcastle University, Newcastle Upon Tyne, UK

J Fam Plann Reprod Health Care 2011;37:58. doi:10.1136/ffprhc.2010.0013 